\title{
Long-term graft patency after coronary artery bypass grafting: Effects of surgical technique
}

\author{
GRIGORE TINICA $^{1,2}$, RALUCA OZANA CHISTOL ${ }^{3}$, DIANA BULGARU ILIESCU ${ }^{4,5}$ and CRISTINA FURNICA ${ }^{5,6}$ \\ ${ }^{1}$ Department of Cardiovascular Surgery, 'Prof. Dr. George I.M. Georgescu' Cardiovascular Diseases Institute, 700503 Iasi; \\ ${ }^{2}$ Discipline of Cardiac Surgery, Department of Surgery I, 'Grigore T. Popa' University of Medicine and Pharmacy, \\ 700115 Iasi; ${ }^{3}$ Department of Medical Imaging, 'Prof. Dr. George I.M. Georgescu' Cardiovascular Diseases Institute, \\ 700503 Iasi; ${ }^{4}$ Discipline of Forensic Medicine, Medical Department III, 'Grigore T. Popa' University of \\ Medicine and Pharmacy, 700115 Iasi; ${ }^{5}$ Institute of Forensic Medicine, 700455 Iasi; ${ }^{6}$ Discipline of Anatomy, \\ Department of Morpho-Functional Sciences I, 'Grigore T. Popa' University of \\ Medicine and Pharmacy, 700115 Iasi, Romania
}

Received May 26, 2018; Accepted October 11, 2018

DOI: $10.3892 /$ etm.2018.6929

\begin{abstract}
The aim of the current study was to identify surgical factors associated with long-term patency of grafts used in coronary artery bypass grafting (CABG). The present study analyzed data from 127 patients who underwent CABG at our institute between 2000 and 2006 and presented for ambulatory examination and coronary computed tomography angiography evaluation of graft patency in $2016(139.78 \pm 36.64$ months post-CABG). The 127 patients received 340 grafts $(2.68$ grafts/patient) and 399 distal anastomoses (3.14 anastomoses/patient), $220(55.14 \%)$ with arterial grafts and 179 (44.86\%) with saphenous vein grafts. Graft patency varied according to coronary territory, proximal anastomosis type (in situ graft, composite graft, graft anastomosed to the ascending aorta), $\mathrm{Y}$ anastomosis angle $\left(47.21^{\circ}\right.$ for patent arterial grafts vs. $56^{\circ}$ for occluded), and distal anastomosis angle (in sequential anastomoses irrespective to graft type, $48.60^{\circ}$ for patent side-to-side anastomosis vs. $53.97^{\circ}$ for occluded, $65.12^{\circ}$ for patent end-to-side anastomosis vs. $90.80^{\circ}$ for occluded; in single end-to-side anastomosis of arterial grafts, $39.46^{\circ}$ for patent and $44.94^{\circ}$ for occluded). A single end-to-side anastomosis angle $60^{\circ}$ or greater was associated with a 5.149 occlusion odds ratio $(\mathrm{OR})(\mathrm{P}<0.001)$ for arterial grafts. Venous grafts were not sensitive to single end-to-side anastomosis angle. In conclusion, a small anastomosis angle for proximal $\mathrm{Y}$ and distal anastomoses is associated with
\end{abstract}

Correspondence to: Dr Raluca Ozana Chistol, Department of Medical Imaging, 'Prof. Dr. George I.M. Georgescu' Cardiovascular Diseases Institute, 50 Carol I Bvd., 700503 Iasi, Romania E-mail: ralucachistol@gmail.com

Key words: coronary artery bypass grafting, long-term patency, anastomosis angle, anastomosis type, composite grafting a higher long-term patency of the free graft. Radial artery grafts registered higher patency rates when anastomosed to the ascending aorta compared with composite grafting with the left internal thoracic artery, whereas in situ right internal thoracic artery (RITA) anastomosed to the right coronary territory is associated with a lower patency rate compared with free RITA used to revascularise the anterolateral or circumflex territory in composite grafting.

\section{Introduction}

In the present, cardiovascular diseases are the leading cause of death worldwide, with an estimated 17,7 million deaths per year of which 7.4 million are attributed to coronary artery disease (CAD) alone (1). Between 18 and 91 per 100,000 inhabitants benefit from coronary artery bypass grafting (CABG) in Europe (2) and, according to both European (3) and American (4) Societies' guidelines, CABG is associated with an increase in quality of life and survival in patients with unprotected left main (or equivalent) and multi-vessel disease; however, the ideal grafting technique has not been established.

Early $\mathrm{CABG}$ interventions were performed almost entirely using saphenous vein grafts (SVG) with a late attrition rate of $2-5 \%$ per year after surgery related to the intrinsic pathologic changes (5). Compared with veins, internal thoracic arteries (ITA) have an extremely low attrition rate with very good long-term patency rates $(96.4 \%$ over 15 years) (6). The use of an ITA graft results in a mean survival of 4.4 years longer than $C A B G$ with veins alone over a 20-year follow-up period (7), and bilateral ITA [left internal thoracic artery (LITA) and right internal thoracic artery (RITA)] use offers even better survival rates than single ITA grafts (8).

Most patients with CAD have a multi-vessel disease and require revascularisation of more than two coronary arteries. The pursuit of additional grafts and anastomosis techniques to achieve complete revascularisation (5-6 distal anastomoses) 
has not proved to be an easy task $(9,10)$. One option is the radial artery (RA), which supplies a long graft with a calibre superior to ITA but is prone to spasm and intimal hyperplasia in case of inadequate harvesting and preparation due to its muscular structure, leading to its abandonment in the early years of CABG (11). Improved harvesting and preparation finally made RA a viable option as a graft superior to SVG in terms of long-term patency $(91.8 \%$ vs. $86.4 \%)(12,13)$. Various teams have proposed alternative grafts (right gastroepiploic artery, inferior epigastric artery, splenic artery, ulnar artery, subcapsular artery, left gastric artery and lateral circumflex femoral artery), but their long-term reliability has not yet been confirmed (14).

Complete revascularisation usually has to be accomplished using two to three grafts with the best-proven patency rates. In these circumstances, sequential, composite, Y-grafts, T-grafts, and combinations are required to bypass all stenosis/occlusions with a limited number of grafts. Buxton described several graft configurations to be used (15) in total arterial revascularisation, but safety, efficacy, and long-term patency have not been assessed for the majority of these configurations (16-18).

The purpose of the current study was to identify surgical factors associated with long-term graft patency.

\section{Patients and methods}

Patient population, surgical technique, and postoperative treatment. Demographic, clinical, echocardiographic, and angiographic data on patients undergoing CABG at the Cardiovascular Diseases Institute in Iasi, Romania, have been retrospectively collected and introduced into a database since 2000 together with intraoperative parameters (extracorporeal circulation type and time, aortic cross clamp time, CABG technique, number and type of grafts, associated procedures) and postoperative data (intensive care unit parameters, complications, and within 30 days mortality). The CABG technique varied according to the international trend at the time of surgery from total venous to total arterial revascularisation and from one graft-one anastomosis to composite and sequential grafting. All interventions were performed by the same experienced primary surgeon $(>7,000$ cardiac surgery interventions performed) using cardiopulmonary bypass (CPB) and continuous sutures with Prolene 8-0 for graft anastomosis. No intraoperative flow measurements were performed.

Long-term postoperative treatment consisted of beta blockers, statins, and enteric-coated aspirin in all cases. Patients who benefited from a RA graft received a calcium channel blocker (Amlodipine) for the first 3 months to prevent spasm. Treatment was adjusted according to the blood pressure, left ventricular ejection fraction (LVEF), and comorbidities.

Patient follow-up. In 2016, the status of all 394 patients who received surgery between 2000 and 2006 and were discharged from the hospital was verified through the National Health Insurance House database, and there were 269 identified survivors (68.27\%). All survivors were recalled for an ambulatory examination and coronary computed tomography angiography (CCTA) evaluation of graft patency by invitation letter submitted to the last known address or by telephonic contact.
Table I. Preoperative data.

\begin{tabular}{|c|c|c|}
\hline Parameter & $\begin{array}{c}\text { Value } \\
\text { (127 patients) }\end{array}$ & Percentage $(\%)$ \\
\hline Mean age (years) $\pm S D$ & $67.54 \pm 8.84$ & - \\
\hline$\leq 65$ years & 44 & 34.65 \\
\hline$>65$ years & 83 & 65.35 \\
\hline Sex, female & 19 & 14.96 \\
\hline Family history & 41 & 32.28 \\
\hline Smoking & 49 & 38.58 \\
\hline Diabetes mellitus & 28 & 22.05 \\
\hline Dyslipidaemia & 97 & 76.38 \\
\hline MAD & 19 & 14.96 \\
\hline AHT & 77 & 60.63 \\
\hline COPD & 8 & 6.30 \\
\hline NYHA II heart failure & 18 & 14.17 \\
\hline NYHA III-IV heart failure & 24 & 18.90 \\
\hline Prior AMI & 65 & 51.18 \\
\hline Arrhythmias & 23 & 18.11 \\
\hline Mean LVEF (\%) & $53.81 \pm 10.77$ & - \\
\hline $\begin{array}{l}\text { Number of affected } \\
\text { coronary arteries }\end{array}$ & $2.86 \pm 1.24$ & - \\
\hline Diffuse disease & 29 & 22.83 \\
\hline Three vessel disease & 71 & 55.91 \\
\hline
\end{tabular}

SD, standard deviation; MAD, multisite artery disease; AHT, arterial hypertension; COPD, chronic obstructive pulmonary disease; NYHA, New York Heart Association; AMI, acute myocardial infarction; LVEF, left ventricular ejection fraction.

A total of 159 patients responded, and the CCTA assessment of graft patency (interpretable images) was performed in 127 patients who had received surgery over 10 years earlier and who consented to and presented no contraindications for the examination. The 127 patients were evaluated after a mean postoperative interval of $139.78 \pm 36.64$ months and represented the study group of the current article. No redo CABG or percutaneous transluminal coronary angioplasty (PTCA) after $\mathrm{CABG}$ were performed in the current study group.

CCTA evaluation. All CCTA evaluations were performed using a 2nd generation 2*128-slices dual source multi-detector CT (MDCT) scanner (Siemens Somatom Definition Flash; Siemens Healthineers, Erlangen, Germany). Optimal reconstructions at different percentage times of an R-R interval were performed $(0.75 \mathrm{~mm}$ slice thickness) and submitted to the Syngo.via workstation (Siemens Healthineers) for image analysis (graft type and status, type of proximal and distal anastomosis, anastomosis angle).

Image analysis. All CT examinations were evaluated twice by the same radiologist for the following parameters: graft type and status (confronted with the operative protocol), proximal 
Table II. Surgical data.

\begin{tabular}{lcc}
\hline Parameter & Value (127 patients) & Percentage $(\%)$ \\
\hline Emergency surgery & 3 & 2.36 \\
Associated interventions & 13 & 10.24 \\
ACC time (min) \pm SD & $90.01 \pm 61.35$ & \\
ECC time (min) \pm SD & $136.82 \pm 64.13$ & \\
Mean number of grafts/patient & $2.68 \pm 0.94$ & \\
Mean number of arterial grafts/patient & $1.64 \pm 1.20$ & 62.20 \\
Mean number of venous grafts/patient & $1.52 \pm 0.79$ & 29.92 \\
Mean number of distal anastomoses/patient & $3.14 \pm 1$ & 3.94 \\
Conventional CABG (at least 1 SVG) & 79 & 3.94 \\
TAR & 38 & 0.79 \\
Single graft & 5 & 80.31 \\
Total venous & 5 & 1
\end{tabular}

Associated interventions: Valve surgery, atrial fibrillation ablation, ascending aorta replacement, left ventricular aneurysm repair. SD, standard deviation; ACC, aortic cross clamp; ECC, extracorporeal circulation; CABG, coronary artery bypass grafting; TAR, total arterial revascularisation; IABP, intra-aortic balloon pump.
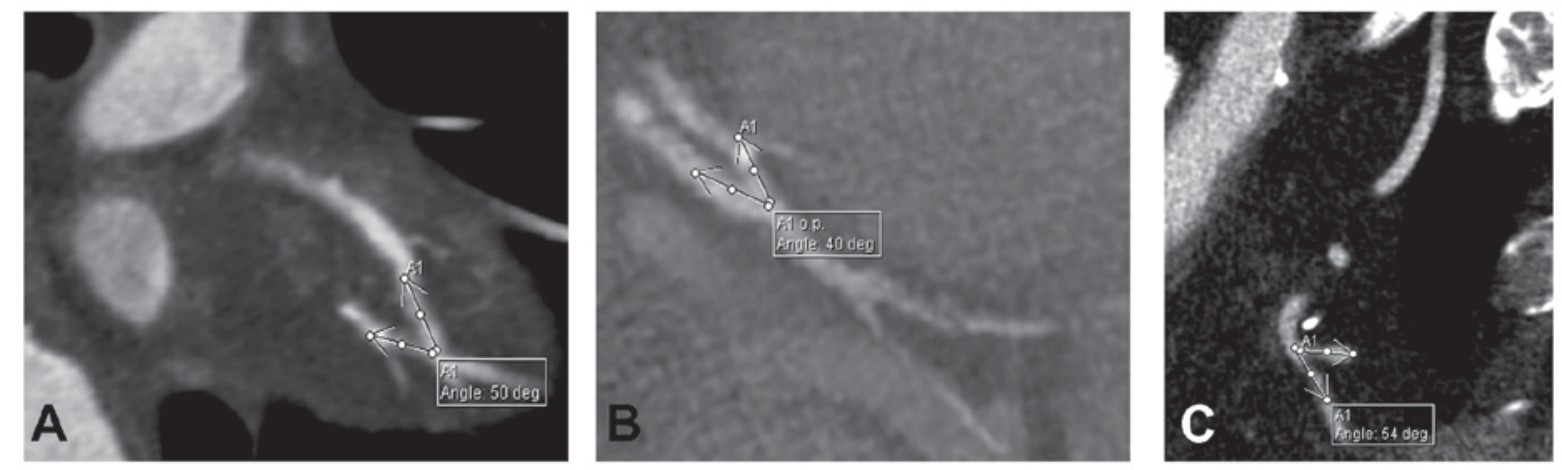

Figure 1. Measurement of (A) distal side-to-side, (B) distal end-to-side and (C) Y anastomosis angle on computerised tomography images.

and distal anastomosis type (confronted with the operative protocol), anastomosis angle ( $\mathrm{Y}$ anastomosis angle measured between the branches of the $\mathrm{Y}$, distal end-to-side and side-to-side anastomosis angle measured between the native vessel and the graft) (Fig. 1). All angles were measured on multiplanar reconstructions (MPR) with the two vessels (graft and native coronary artery) in the same plane.

Statistical analysis. Continuous variables are expressed as mean \pm standard deviation (SD) and categorical variables as percentages. Groups were compared using the chi-square test for categorical variables, and the Student $t$ test and Wilcoxon-Mann-Whitney $U$ test for continuous variables on the basis of their distribution. Normality was verified using the Kolmogorov-Smirnov and the Shapiro-Wilk W tests. Logistic regression was employed for testing the association between categorical and continuous variables previously identified as affecting the outcome (graft patency) at univariable analysis with $\mathrm{P}<0.05$. A receiver operating characteristic (ROC) curve was used for identifying discrimination threshold (cut-off) value for continuous variables. Statistical analyses were performed using SPSS Statistics 24 for Mac OS X (IBM, Corp., Armonk, NY, USA).

The study was approved by the Ethics Committee of the 'Grigore T. Popa' University of Medicine and Pharmacy (Iasi, Romania) and by the Ethics Committee of the 'Prof. Dr. George I.M. Georgescu' Cardiovascular Diseases Institute (Iasi, Romania).

\section{Results}

Baseline characteristics. The preoperative, operative, and postoperative data of the 127 patients are summarised in Tables I-III.

Graft patency assessment. The 127 patients presented a total number of 340 grafts (2.68 grafts/patient) and 399 distal anastomoses (3.14 anastomoses/patient), 220 (55.14\%) performed using arterial grafts (122 LITA, 53 RA, 45 RITA) and 179 (44.86\%) using SVG. Overall graft patency at 10 to 16 years after 
Table III. Postoperative data (initial 30 days).

Value

Parameter

(127 patients)
Percentage

7.87

1.57

24.41

1.57

1.57

2.36

3.15

Digestive complications

(ileus, Clostridium difficile infection)

Table IV. Graft patency according to coronary territory.

\begin{tabular}{llcl}
\hline Variable & Right coronary territory $(\%)$ & Circumflex artery territory (\%) & Anterolateral territory (\%) \\
\hline $\begin{array}{l}\text { Right internal thoracic } \\
\text { artery graft }\end{array}$ & $\begin{array}{l}3 \text { occluded grafts out of } \\
8(37.5)\end{array}$ & 7 occluded grafts out of 23 (30.43) & $\begin{array}{l}1 \text { occluded graft out of } \\
14(7.14)\end{array}$ \\
Radial artery graft & $\begin{array}{l}\text { 6 occluded grafts out of } \\
\text { 31 (19.35) }\end{array}$ & 4 occluded grafts out of 16 (25) & $\begin{array}{l}1 \text { occluded graft out of } \\
6(16.67)\end{array}$ \\
Saphenous vein graft & $\begin{array}{l}24 \text { occluded grafts out of } \\
\text { 68 (35.29) }\end{array}$ & 11 occluded grafts out of 63 (17.46) & $\begin{array}{l}11 \text { occluded graft out of } \\
48(22.92)\end{array}$ \\
\hline
\end{tabular}

Table V. Association of RA graft patency with proximal anastomosis type.

\begin{tabular}{lcccr}
\hline Variable & Occluded $(\%)$ & Patent $(\%)$ & Pearson chi-square & P-value \\
\hline RA-Aorta & $6(15)$ & $34(85)$ & 10.932 & 0.001 \\
RA-LITA & $5(38.46)$ & $8(61.54)$ & & \\
\hline
\end{tabular}

RA, radial artery; LITA, left internal thoracic artery.

the surgical intervention was of $90.16 \%$ for LITA (12 occluded grafts), $75.55 \%$ for RITA (11 occluded grafts), $79.25 \%$ for RA (11 occluded grafts), and $74.3 \%$ for SVG (46 occluded grafts) with variations according to coronary territory (Table IV).

The effect of proximal anastomosis type. In case of RITA and RA, the authors analysed graft patency according to proximal anastomosis type (in situ graft, composite graft with Y/T anastomosis, and graft anastomosed to the ascending aorta). All saphenous vein grafts were anastomosed proximally to the ascending aorta, and LITA was used in situ in all cases except one so both grafts were excluded from this analysis.

RITA was used in situ in 8 cases (17.78\%), as a composite graft anastomosed Y/T to LITA in 36 cases (80\%), and as a free graft anastomosed to the ascending aorta in 1 case (2.22\%). The occlusion rate was of $3 / 8(37.5 \%)$ for in situ RITA and $8 / 3936(22.22 \%)$ for composite grafting. The free graft anastomosed to the ascending aorta was patent. Chi-square test showed no association of RITA patency with proximal anastomosis type $(\mathrm{P}=0.501)$.
RA was used as a free graft anastomosed to the ascending aorta in 40 cases $(75.47 \%)$ with an occlusion rate of $6 / 40$ (15\%) and as a composite graft anastomosed Y/T to LITA in 13 cases $(25.43 \%)$ with an occlusion rate of $5 / 13(38.46 \%)$. The Pearson chi-square test proved a significant association of graft patency with proximal anastomosis type $\left(\chi^{2}=10.932\right.$, $\mathrm{P}=0.001$ ) (Table V). Logistic regression showed a $0.110 \mathrm{OR}$ $(\mathrm{P}=0.002)$ for RA anastomosed to the ascending aorta, thus certifying a protective effect against graft failure (Table VI).

The effect of Y/T anastomosis angle. The mean angle for $\mathrm{Y} / \mathrm{T}$ anastomoses with both grafts patent was $47.21^{\circ}$ compared with $56^{\circ}$ for anastomoses with occlusion of the free arterial graft (RA or RITA). The Wilcoxon-Mann-Whitney U test identified a significant difference between the anastomosis angle of patent vs. occluded grafts $(\mathrm{P}=0.015)$, a smaller angle being registered in case of patent anastomosis (Table VII) (Fig. 2). The authors did not identify a high sensitivity and specificity threshold angle with prognostic value in affirming the risk of occlusion for Y-anastomoses. 
Table VI. Prognostic value of the proximal anastomosis type (RA-aorta).

$95 \% \mathrm{CI}$ for $\mathrm{EXP}(\mathrm{B})$

B

SE

Wald

Df

Sig.

$\operatorname{Exp}(\mathrm{B})$

Lower

Upper

Proximal anastomosis

$-2.205$

0.722

9.327

1

0.002

0.110

0.027

0.454

Constant

0.470

0.570

0.680

1

0.410

1.600

RA, radial artery; B, unstandardized regression weight; SE, standard error; Wald, Wald chi-square test; Df, degrees of freedom; Sig., significance level; $\operatorname{Exp}(\mathrm{B})$, exponentiation of the B coefficient; CI, confidence interval.

Table VII. Proximal and distal anastomosis angle comparison between occluded and patent grafts.

\begin{tabular}{|c|c|c|c|}
\hline Variable & Occluded & Patent & P-value \\
\hline $\mathrm{Y} / \mathrm{T}$ anastomosis angle & $56 \pm 27.22^{\circ}$ & $47.21 \pm 25.05^{\circ}$ & 0.015 \\
\hline Side-to-side anastomosis (sequential grafting) & $53.97 \pm 23.54^{\circ}$ & $48.60 \pm 21.14^{\circ}$ & 0.005 \\
\hline End-to-side anastomosis (sequential grafting) & $90.80 \pm 11.27^{\circ}$ & $65.12 \pm 26.04^{\circ}$ & 0.002 \\
\hline End-to-side (single distal anastomosis) & $44.94 \pm 19.38^{\circ}$ & $39.46 \pm 18.71^{\circ}$ & 0.034 \\
\hline
\end{tabular}

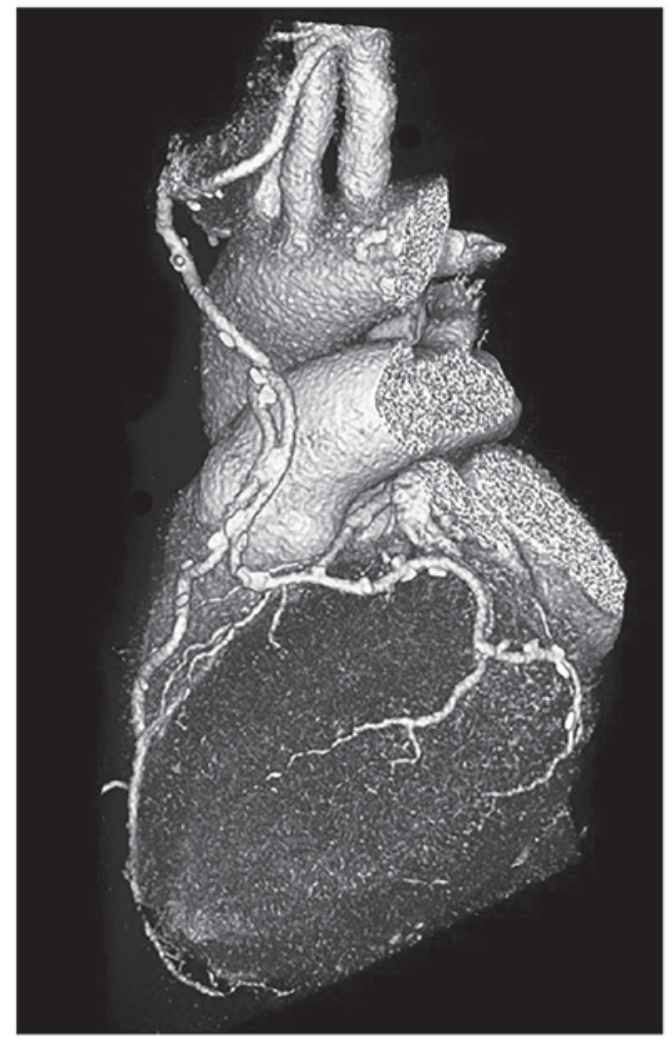

Figure 2. Coronary computed tomography angiography reconstruction demonstrating a proximal $\mathrm{Y}$ anastomosis of the right internal thoracic artery with the left internal thoracic artery. The left internal thoracic artery was used in situ and the right internal thoracic artery as a free graft with sequential distal anastomoses to CX territory.

The effect of distal anastomosis type and angle. In case of distal anastomosis, 31 were side-to-side performed with 27

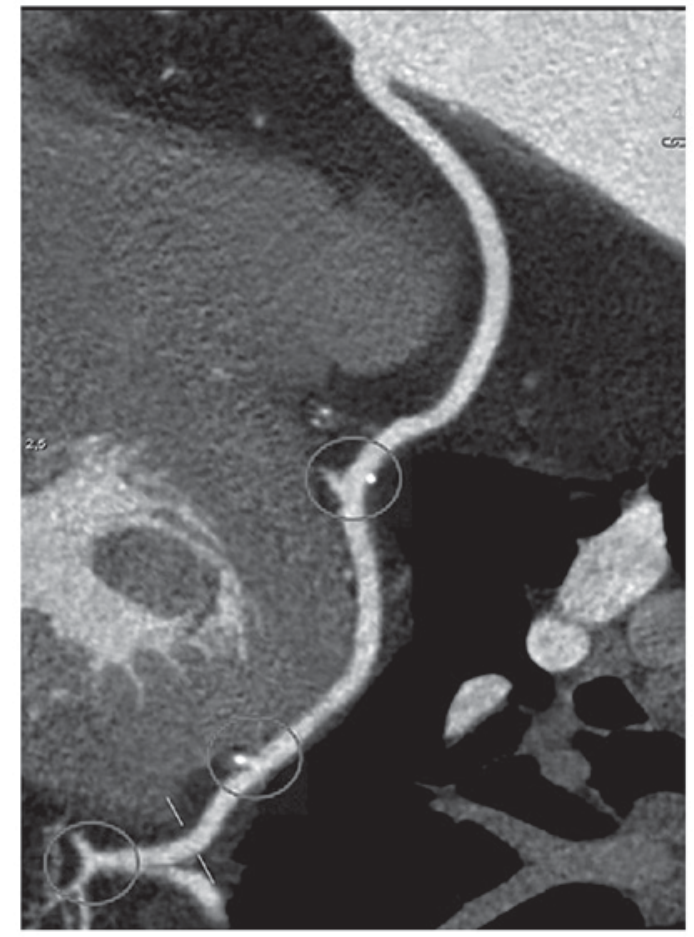

Figure 3. saphenous vein graft with two side-to-side anastomoses used to revascularise CX territory.

sequential grafts, the rest of 368 being end-to-side (Fig. 3). Of the 27 sequential grafts, 9 were venous (occlusion of 2 end-to-side anastomoses and 0/11 side-to-side anastomoses) and 18 arterial (occlusion of 7 end-to-side anastomoses and 9/20 side-to-side anastomoses). The small number of cases did not allow statistical interpretation, but one can note a higher patency rate of venous grafts with sequential anastomoses. 
Table VIII. Prognostic value of a distal anastomosis angle $\geq 60^{\circ}$.

95\% CI for $\operatorname{EXP}(\mathrm{B})$

\begin{tabular}{lcccccccr} 
B & SE & Wald & Df & Sig. & $\operatorname{Exp}(\mathrm{B})$ & Lower & Upper & Occluded anastomoses \\
\hline $\begin{array}{c}\text { Angle } \\
\begin{array}{l}1.639 \\
\text { Constant }\end{array}\end{array}$ & 0.444 & 13.630 & 1 & $<0.01$ & 5.149 & 2.157 & 12.292 & $14(8.38 \%)$ for $<60^{\circ}$ \\
-2.367 & 0.302 & 61.476 & 1 & $<0.01$ & 0.094 & & & $6(17.14 \%)$ for $\geq 60^{\circ}$ \\
\hline
\end{tabular}

B, unstandardized regression weight; SE, standard error; Wald, Wald chi-square test; Df, degrees of freedom; Sig., significance level; Exp(B), exponentiation of the B coefficient; CI, confidence interval.

Concerning the anastomosis angle in sequential grafting, the angle was of $48.60^{\circ}$ for patent side-to-side anastomoses compared with $53.97^{\circ}$ for occluded ones. Similarly, the anastomosis angle was smaller for patent end-to-side anastomoses $\left(65.12^{\circ}\right)$ compared with occluded ones $\left(90.80^{\circ}\right)(\mathrm{P}=0.002)$ (Table VII). The analysis was performed irrespective to graft type.

In case of single distal anastomosis (end-to-side), arterial grafts proved to be sensitive to the anastomosis angle with a mean value of $39.46^{\circ} \pm 21.97^{\circ}$ for patent grafts and $44.94^{\circ} \pm 29.52^{\circ}$ for occluded ones $(\mathrm{P}=0.034$ ) (Table VII). For venous grafts, the difference was not statistically significant. Using the area under the curve (AUC) of ROC, an angle of $60^{\circ}$ was determined as a threshold value with an $80 \%$ sensitivity and specificity in affirming arterial graft occlusion (Fig. 4). Logistic regression identified an occlusion OR of 5.149 for arterial grafts in case of distal anastomosis angle of $60^{\circ}$ or greater $(\mathrm{P}<0.001)$ (Table VIII).

\section{Discussion}

Over the decades, graft patency has been assessed for individual grafts alone and not for CABG as an entity per se, while the dilemma of designing an optimal grafting technique bringing considerable haemodynamic improvement and graft patency remained unsolved despite the increase in worldwide research. A literature review allowed us to classify factors influencing graft patency into morphological (vessel type, graft length, and calibre) $(11,15)$, pathophysiological (competitive flow through the native coronary artery, graft degenerative changes) (15), and surgical (technical expertise, graft harvesting and preparation, grafting design, and anastomosis technique) categories $(16,17)$. This single-centre study analysed graft patency according to surgical technique, namely proximal and distal anastomosis type and angle.

Proximal anastomosis. We found a higher patency rate for RITA used as a composite graft for the anterolateral or CX territory (78.38\%) compared with in situ RITA graft for the RCA territory $(62.5 \%)$ and for RA anastomosed to the ascending aorta (85\%) compared with composite grafting with LITA $(61.54 \%)$.

A number of studies (18-22) analysed the patency of in situ and free pedicled ITAs. Dion et al prefer an in situ

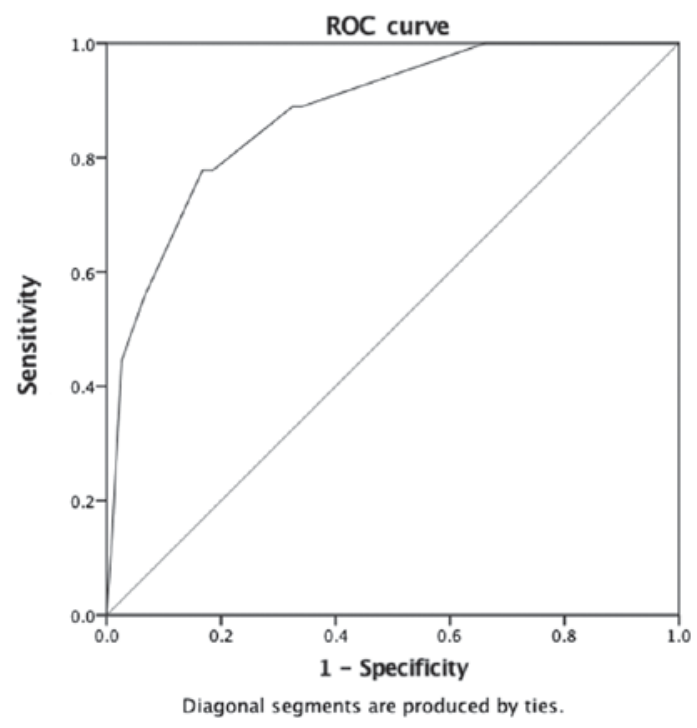

Figure 4. ROC curve fr identifying the cut-off value of the distal anastomosis angle. ROC, receiver operating characteristic.

pedicled ITA each time the local anatomy, the topography, and number of lesions allow it, the physiological response being predictable in terms of flow and calibre according to their study (23). They evaluated ITA grafts irrespective of type and target coronary territory at 7.5 years from surgery and found a patency rate of $96.3 \%$ for in situ ITAs compared with $86.5 \%$ for free grafts anastomosed to the ascending aorta or used for $\mathrm{Y} / \mathrm{T}$ anastomosis.

Fukui, Calafiore, and Tatoulis consider, based on angiographic results obtained at 12 months, 17.5 months, and 41,5 months postoperatively, that there are no differences in patency rates and prognosis between free ITAs with composite anastomosis and in situ ITAs on one hand and between pedicled and skeletonised grafts on the other hand (19-21). In our study, in situ RITA was used exclusively for the RCA territory and free ITAs as composite grafts for the anterolateral or CX territory, thus introducing another variable in the equation, the coronary territory. In 2012, Mukherjee et al performed a meta-analysis on 226 articles to compare the outcome of RITA and SVG used to revascularise the right coronary territory and concluded that SVG may offer a superior patency rates when used to revascularise RCA compared with RITA (23). The poor outcome of RITA grafted to the right coronary territory could 
be explained by graft stretching in cases of left ventricular dilation, different haemodynamic conditions, and runoff.

In our group, RA was used as a free graft with a higher patency rate when anastomosed to the ascending aorta vs. composite grafting. Similar results were previously reported in 2009 by Jung et al, who analysed 893 patients that benefited from RA grafts, 451 with direct RA to aortic anastomosis (group I) and 422 with RA composite grafting with the LITA (group II). The patency rate was significantly higher in group I than in group II in the early postoperative period (98.3\% vs. $94.5 \%)$, at 1 year (93.8 vs. 90.5\%), 2 years (90.5\% vs. $85.3 \%)$, and 5 years $(74.3 \%$ vs. $65.2 \%)$. Jung et al attribute the difference to a higher drive pressure and flow afforded by the direct aortic connection, thus preventing occlusion (24).

In case of composite grafting, the long-term patency was conditioned by the anastomosis angle, with smaller values in cases of patent free graft $\left(47.21^{\circ}\right)$ compared with occluded free graft $\left(56^{\circ}\right)$. No in vivo study analysing $\mathrm{Y}$ anastomosis angle was identified in the literature. Experimental research performed by Song et al using three-dimensional simulation of a Y anastomosis by computational fluid dynamics support our results by demonstrating that the more acute is the angle of anastomosis, the smaller are the energy loss and the back flow into the graft (25).

Distal anastomosis. Compared to venous grafts, arterial grafts also proved sensitive to distal anastomosis angle, with a mean value of $39.46^{\circ}$ for patent grafts vs. $44.94^{\circ}$ for occluded ones and a 5.149 occlusion OR in cases of distal anastomosis angle $60^{\circ}$ or greater for grafts with single end-to-side anastomosis. The first efforts to imagine an optimal distal anastomosis technique aimed to improve local haemodynamics by changing the anastomosis geometry, as tissue remodelling is influenced by the end-to-side anastomosis angle, a factor conditioning flow fields and wall shear stress (WSS) (26). Staalsen et al demonstrated using polyurethane grafts that no flow disturbances were detected at the toe and one diameter downstream with an anastomosis angle of $15^{\circ}$, and a zone of recirculation extending from the toe to one diameter downstream was identified in the $45^{\circ}$ and $90^{\circ}$ anastomoses. An anastomosis angle of $30^{\circ}$ is generally associated with a uniform flow and a smooth transition between graft flow and target vessel flow (26).

Similar results were obtained for sequential anastomosis, with an angle of $48.60^{\circ}$ for patent side-to-side anastomoses compared with $53.97^{\circ}$ for occluded and $65.12^{\circ}$ for patent end-to-side anastomoses vs. $90.80^{\circ}$ for occluded irrespective of graft type. One can notice wider anastomoses angles for distal end-to-side anastomoses of sequential grafts compared with grafts with single distal anastomosis. The final anastomosis of side-to-side grafts is usually performed with posterolateral arteries on the diaphragmatic surface of the heart or with the posterior descending artery, thus explaining a wider angle compared with grafts with single distal anastomosis performed with diagonal or marginal arteries. In cases of sequential anastomoses, Frauenfelder et al (27) and Fei et al (28) demonstrated that wider anastomotic angles generate higher WSS values and flow oscillation around the toe and along the bed of the target vessel. These studies consider the graft and target vessel as forming a planar configuration, which is far from reality, but similar results were obtained by Sherwin et al (29), who investigated the influence of out-of-plane geometry and found that the anastomosis bed was most affected by flow oscillation generated by wider anastomoses angles yielding to intimal hyperplasia and long-term occlusion.

Bonert et al (30) compared the patency of side-to-side with end-to-side anastomoses and concluded that the parallel form of side-to-side anastomosis contributes to maintaining graft patency in side-to-side anastomoses by diminishing the haemodynamic risk and spatial gradients. In cases of end-to-side anastomosis, the haemodynamic forces act perpendicular to the target vessel wall and trigger important variations of WSS (1.5 Pa) and formation of stagnation and flow separation zones (29). In our study, the limited number of sequential anastomoses did not allow a statistically significant comparison of side-to-side to end-to-side anastomoses, but venous grafts proved to have a higher patency with side-to-side anastomoses compared with arterial ones.

Although limited by the small sample and reduced number of cases for each graft configuration, our study is the first to quantify potential factors conditioning graft patency on CCTA images, as there is a paucity of in vivo studies examining morphological, pathophysiological, and surgical factors that influence long-term graft patency. Morphological factors (e.g., graft length, target vessel calibre, graft-to-host diameter ratio, degree of stenosis) were analysed together with surgical factors and will be the subject of a different article. Currently, the majority of the research in the field is carried on in in vitro or computerised models that cannot take into account all possible graft configurations. Tremblay et al (31) performed the only study up to date that uses CCTA to identify morphological and morphometrical factors associated with a saphenous vein bridge (SVB) dysfunction. They analysed SVB length, SVB segment lengths, SVB lumen sectional areas, anastomostic angulations and intrinsic SVB angulations on a group of 40 patients and concluded that $\mathrm{CT}$ could be used to identify quantitative graft parameters associated with graft dysfunction. Our study extends this idea and identifies morphological and morphometrical factors associated with long-term graft patency according to graft type, grafted territory, anastomosis type and angle; factors that could lead to adjustment of the surgical technique to increase long-term patency rates and reduce the risk of major adverse cardiac events. Bias was controlled as much as possible by analysing data according to the aforementioned factors, all cases being operated by the same surgical team. The current research is to be considered a pilot study and will be further extended by systematic recall of patients who received surgery more than 10 years ago for a specific analysis focused on target vessels, especially the RCA.

In conclusion, surgical technique is an important factor conditioning long-term graft patency. A small anastomosis angle, both for proximal $\mathrm{Y}$ and distal anastomoses, is associated to a higher long-term patency of the free graft. RA grafts registered higher patency rates when anastomosed to the ascending aorta compared with composite grafting with LITA, whereas in situ RITA anastomosed to the right coronary territory is associated with a lower patency rate compared with free RITA used to revascularise the anterolateral or CX territory as part of composite grafting. 


\section{Acknowledgements}

Not applicable.

\section{Funding}

The scientific research was financed by the 'Grigore T. Popa' University of Medicine and Pharmacy under the contract no. 29031/28.12.2016.

\section{Availability of data and materials}

The datasets used and/or analyzed during the current study are available from the corresponding author on reasonable request.

\section{Authors' contribution}

GT was the primary surgeon who designed the study and revised the manuscript. ROC evaluated and quantified graft patency, performed the statistical analysis and participated in writing the manuscript. DBI digitized patient data, contributed to the study design, offered ethics counselling and assisted with literature research. CF was a major contributor in writing the manuscript, participated in collecting patient data, counselled statistical analysis and revised the manuscript. All authors read and approved the final manuscript.

\section{Ethics approval and consent to participate}

The study was approved by the Ethics Committees of the 'Prof. Dr. George I.M. Georgescu' Cardiovascular Institute and 'Grigore T. Popa' University of Medicine and Pharmacy. All patients provided written informed consent prior to their inclusion in the study.

\section{Patient consent for publication}

Written informed consent for the publication of any associated data and accompanying images was obtained from all patients included in the study.

\section{Competing interests}

The authors declare that they have no competing interests.

\section{References}

1. Eurostat-Cardiovascular diseases statistics: Available from: http://ec.europa.eu/eurostat/statistics-explained/index. php/Cardiovascular_diseases_statistics. Accessed August 31, 2017.

2. Eurostat-Surgical operations and procedures statistics. Available from: http://ec.europa.eu/eurostat/statistics-explained/index. php/Surgical_operations _and_procedures_statistics. Accessed August 31, 2017.

3. Authors/Task Force members, Windecker S, Kolh P, Alfonso F, Collet JP, Cremer J, Falk V, Filippatos G, Hamm C, Head SJ, et al 2014 ESC/EACTS guidelines on myocardial revascularization: The Task Force on Myocardial Revascularization of the European Society of Cardiology (ESC) and the European Association for Cardio-Thoracic Surgery (EACTS) Developed with the special contribution of the European Association of Percutaneous Cardiovascular Interventions (EAPCI). Eur Heart J 35: 2541-2619, 2014
4. Coronary Revascularization Writing Group, Patel FR, Dehmer GJ, Hirshfeld JW, Smith PK, Spertus JA, Technical Panel, Masoudi FA, Dehmer GJ, Patel MR, et al: ACCF/SCAI/STS/AATS/AHA/ASNC/HFSA/SCCT 2012 appropriate use criteria for coronary revascularization focused update: A report of the American College of Cardiology Foundation Appropriate Use Criteria Task Force, Society for Cardiovascular Angiography and Interventions, Society of Thoracic Surgeons, American Association for Thoracic Surgery, American Heart Association, American Society of Nuclear Cardiology, and the Society of Cardiovascular Computed Tomography. J Thorac Cardiovasc Surg 143: 780-803, 2012

5. Sabik JF III: Understanding saphenous vein graft patency. Circulation 124: 273-275, 2011.

6. Tatoulis J, Buxton BF and Fuller JA: Patencies of 2127 arterial to coronary conduits over 15 years. Ann Thorac Surg 77: 93-101, 2004.

7. Cameron AA, Green GE, Brogno DA and Thornton J: Internal thoracic artery grafts: 20-year clinical follow-up. J Am Coll Cardiol 25: 188-192, 1995.

8. Taggart DP, D'Amico R and Altman DG: Effect of arterial revascularisation on survival: A systematic review of studies comparing bilateral and single internal mammary arteries. Lancet 358: 870-875, 2001.

9. Georghiou GP, Vidne BA and Dunning J: Does the radial artery provide better long-term patency than the saphenous vein? Interact Cardiovasc Thorac Surg 4: 304-310, 2005.

10. Petrovic I, Nezic D, Peric M, Milojevic P, Djokic O, Kosevic D, Tasic N, Djukanovic B and Otasevic P: Radial artery vs saphenous vein graft used as the second conduit for surgical myocardial revascularization: Long-term clinical follow-up. J Cardiothorac Surg 10: 127, 2015.

11. Aydin S, Aydin S, Nesimi Eren M, Sahin I, Yilmaz M, Kalayci M and Gungor O: The cardiovascular system and the biochemistry of grafts used in heart surgery. Springerplus 2: 612, 2013.

12. Buxton BF and Hayward PA: The art of arterial revascularization-total arterial revascularization in patients with triple vessel coronary artery disease. Ann Cardiothorac Surg 2: 543-551, 2013.

13. Drouin A, Noiseux N, Chartrand-Lefebvre C, Soulez G, Mansour S, Tremblay JA, Basile F, Prieto I and Stevens LM: Composite versus conventional coronary artery bypass grafting strategy for the anterolateral territory: Study protocol for a randomized controlled trial. Trials 14: 270, 2013.

14. Ohira S, Doi K, Okawa K, Dohi M, Yamamoto T, Kawajiri H and Yaku H: Safety and efficacy of sequential left internal thoracic artery grafting to left circumflex area. Ann Thorac Surg 102: 766-773, 2016.

15. Porto I, Gaudino M, De Maria GL, Di Vito L, Vergallo R, Bruno P, Bonalumi G, Prati F, Bolognese L, Crea F and Massetti M: Long-term morphofunctional remodeling of internal thoracic artery grafts: A frequency-domain optical coherence tomography study. Biomed Eng Online 6: 269-276, 2013.

16. Ghista DN and Kabinejadian F: Coronary artery bypass grafting hemodynamics and anastomosis design: A biomedical engineering review. Biomed Eng Online 12: 129, 2013.

17. Li H, Xie B, Gu C, Gao M, Zhang F, Wang J, Dai L and Yu Y: Distal end side-to-side anastomoses of sequential vein graft to small target coronary arteries improve intraoperative graft flow. BMC Cardiovasc Disord 14: 65, 2014.

18. Dion R, Glineur D, Derouck D, Verhelst R, Noirhomme P, El Khoury G, Degrave E and Hanet C: Long-term clinical and angiographic follow-up of sequential internal thoracic artery grafting. Eur J Cardiothorac Surg 17: 407-714, 2000.

19. Calafiore AM, Contini M, Vitolla G, Di Mauro M, Mazzei V, Teodori G and Di Giammarco G: Bilateral internal thoracic artery grafting: Long-term clinical and angiographic results of in situ versus Y grafts. J Thorac Cardiovasc Surg 120: 990-996, 2000.

20. Tatoulis J, Buxton BF and Fuller JA: Patencies of 2127 arterial to coronary conduits over 15 years. Ann Thorac Surg 77: 93-101, 2004.

21. Fukui S, Fukuda H, Toda K, Yoshitatsu M, Funatsu T, Masai T and Miyamoto Y: Remodeling of the radial artery anastomosed to the internal thoracic artery as a composite straight graft. J Thorac Cardiovasc Surg 134: 1136-1142, 2007.

22. Taggart DP: Current status of arterial grafts for coronary artery bypass grafting. Ann Cardiothorac Surg 2: 427-430, 2013 
23. Mukherjee D, Cheriyan J, Kourliouros A and Athanasiou T: Does the right internal thoracic artery or saphenous vein graft offer superior revascularization of the right coronary artery? Interact Cardiovasc Thorac Surg 15: 244-247, 2012.

24. Jung SH, Song H, Choo SJ, Je HG, Chung CH, Kang JW and Lee JW: Comparison of radial artery patency according to proximal anastomosis site: Direct aorta to radial artery anastomosis is superior to radial artery composite grafting. J Thorac Cardiovasc Surg 138: 76-83, 2009.

25. Song MH, Sato M and Ueda Y: Three-dimensional simulation of coronary artery bypass grafting with the use of computational fluid dynamics. Surg Today 30: 993-998, 2000

26. Staalsen NH, Ulrich M, Winther J, Pedersen EM, How T and Nygaard H: The anastomosis angle does change the flow fields at vascular end-to-side anastomoses in vivo. J Vasc Surg 21: 460-471, 1995

27. Frauenfelder T, Boutsianis E, Schertler T, Husmann L, Leschka S, Poulikakos D, Marincek B and Alkadhi H: Flow and wall shear stress in end-to-side and side-to-side anastomosis of venous coronary artery bypass grafts. Biomed Eng Online 6: 35 2007.
28. Fei DY, Thomas JD and Rittgers SE: The effect of angle and flow rate upon hemodynamics in distal vascular graft anastomoses: A numerical model study. J Biomech Eng 116: 331-336, 1994.

29. Sherwin SJ, Doorly DJ, Franke P and Peiró J: Unsteady near wall residence times and shear exposure in model distal arterial bypass grafts. Biorheology 39: 365-371, 2002.

30. Bonert M, Myers JG, Fremes S, Williams J and Ethier CR: A numerical study of blood flow in coronary artery bypass graft side-to-side anastomoses. Ann Biomed Eng 30: 599-611, 2002.

31. Tremblay JA, Stevens LM, Chandonnet M, Soulez G, Basile F, Prieto I, Noiseux $\mathrm{N}$ and Chartrand-Lefebvre C: A morphometric 3D model of coronary artery bypass graft dysfunction with multidetector computed tomography. Clin Imaging 39: 1006-1011, 2015.

This work is licensed under a Creative Commons Attribution-NonCommercial-NoDerivatives 4.0 International (CC BY-NC-ND 4.0) License. 